Bangladesh Journal of Anatomy July 2013, Vol. 11, No. 2 pp. 81-85

\title{
Study of the Morphological Characteristics of the Human Gallbladder in Relation to Age and Sex of Bangladeshi People
}

\author{
Khalilur Rahman ${ }^{1}$, Afruza Bulbul Akhter², Selina Anwar ${ }^{3}$, Anjum Ara Begum ${ }^{4}$, \\ Sultan Ahmed ${ }^{5}$, Narayan Chandra Saha ${ }^{5}$
}

\begin{abstract}
Context: Variations in the morphology of the gallbladder have long been debated by the abdominal surgeons. So it is important for the surgeons to appreciate the possible anatomical variations that can be encountered during surgery to prevent post operative complications during cholecystectomy. This study was aimed at to find out any variations in the morphology of the postmortem gallbladder in adult Bangladeshi male and female to find out any difference in the gallbladder morphology in relation to age and sex.
\end{abstract}

Material \& methods: This study was done on sixty (60) human postmortem gallbladder from Bangladeshi male and females of two age groups- group $A$ age between 20-40 years and group $B$ age between 41-65 years. Among the morphological parameters length, breadth, thickness and volume of the gallbladders were measured.

Result: Result of the present study showed that the mean values of gross morphological features of the gall bladder (length, breadth, thickness, volume \& weight), were higher in group B than group A except the thickness in female which show somewhat higher mean value in group $A$ than group $B$. The result showed significantly high value for length and volume in case of male only $(p<.05)$ in group $B$ than group $A$. When comparison were made between these values in regard of sex, it was found that males of group $B$ showed higher mean value for all parameters than females of group $B$ and result showed a significantly higher value for the length of gallbladder $(p<.05)$. But in case of group $A$, whereas male had higher mean value for length and weight and, female had higher mean value for breadth, thickness and volume though no values were significantly different.

Conclusion: The higher mean values of different parameters of the gallbladder in elderly males and also from their female counterparts of the same age groups may be due to shorter size of the females. Again some parameters showed higher values in females (breadth, thickness and volume) which may indicate the predominance of cholelithiasis in females. Again most of the values in male and female of elderly were higher than the younger groups indicate the formation of gallstones in elderly.

Key words: Morphology, gall bladder, human.

\section{Introduction}

Gallbladder is a distensible muscular sac that is necessary for the storage and concentration of

1. Associate Professor, Department of Anatomy, Kasir Uddin Medical College, Rangpur

2. Professor, Department of Anatomy, Rangpur Community Medical College, Dhaka

3. Professor, Department of Anatomy, Rangpur Medical College, Dhaka

4. Professor, Department of Anatomy, Prime Medical College, Dhaka

5. Associate Professor, Department of Anatomy, Rangpur Medical College, Dhaka

Correspondence: Dr. Khalilur Rahman bile for the digestion of fatty meal. Billiary diseases are the common health problem throughout the world. The most common biliary diseases are cholelethiasis. Up to $25 \%$ of all Bangladeshi people have gallstones ${ }^{1}$. Traditionally it is believed that cholithiasis is more common in person over 40, especially in women and the obese ${ }^{2}$. According to Zahrani and Mansoor ${ }^{3}$ the male-female ratio was 44.5:1 but Bekele and Tegegn ${ }^{4}$ stated that the male to female ratio was 1:5. No published data regarding the male-female ratio of cholelithiasis in Bangladesh was found. Cholecystectomy is the only treatment for gallstone as no medical treatment is 
still available ${ }^{5}$. Knowledge of relevant anatomy would be important for the safe execution of any operative procedure. Specifically in the context of a cholecystectomy, it has been recognized since long that misinterpretation of normal anatomy as well as the presence of anatomical variations contribute to the occurrence of major postoperative complications especially biliary injuries ${ }^{6}$. Such injuries in turn can cause significant morbidity and occasionally even mortality. They are also one of the commonest causes of litigation against abdominal surgeons in the developed world ${ }^{7}$. So, knowing about the position, shape, size and thickness of gallbladder wall have clinical implication.

There is no widely available published data on morphological variations of gallbladder of autopsy people and also morphological variations of gallbladder in different ages and sexes in Bangladeshi people. All the existing literatures were found from foreign countries. So this study would reveal the morphological structure of gallbladder and help to compare the data of different ages and sexes of Bangladeshi people with foreign country.

With the above background and rationale, the present study was aimed at to study the anatomical features (morphology) of human gallbladder (autopsied) to establish a normal standard for Bangladeshi people and to find out any variation of morphology of gallbladder in relation to age and sex.

\section{Materials and methods}

The present study was carried out on 60 (sixty) post mortem gallbladder collected from
Bangladeshi adult people. The collected samples were divided into groups depending on age and sex (table-I) according to Wikipedia contributors $^{8}$. All the specimens of gallbladder were collected from unclaimed dead bodies from the post mortem examination room of the Department of Forensic Medicine of Rangpur Medical College, Rangpur autopsied on different dates from July, 2008 to June 2009. Samples were collected with the prior permission of the concerned authority

Length $(\mathrm{cm})$, breadth $(\mathrm{cm})$ and thickness $(\mathrm{mm})$ of the gallbladder wall was measured with a slide caliper with Vernier scale. The length of the gallbladder was measured from fundus to neck.

The breadth was measured at the fundus, body, and neck and the average of these three measurements was represented as the breadth of the gallbladder in centimeter.

The inferior surface of gallbladder was incised and the thickness of the gallbladder wall was measured from three points first at the fundus wall, second at the body wall, third at the neck wall. The average was taken as the thickness of the gallbladder in millimeter.

The gallbladder was sectioned from the cystic duct at the junction of the neck of gallbladder and cystic duct and removed from the gallbladder fossa and its weight was measured in grams.

\section{Results}

Table-II shows the results of different parameters of morphology of the gall bladder.

Table -I

Distribution of samples in relation to age and sex for gross morphological study

\begin{tabular}{ccccc}
\hline Group & Age limit & \multicolumn{2}{c}{ No of gallbladder with cystic duct } & Total \\
\cline { 3 - 5 } & & Male & Female & \\
\hline A & $20-40$ years & 18 & 16 & \\
B & $41-65$ years & 14 & 12 & 60 \\
\hline & Total & 32 & 28 & \\
\hline
\end{tabular}


Bangladesh J. Anat. 2013; 11(2) : 81-85

Table-II

Morphological parameters of the gall bladder in relation to age and sex

\begin{tabular}{|c|c|c|c|c|c|}
\hline \multirow[t]{2}{*}{ Characteristics } & \multicolumn{2}{|c|}{ Group A } & \multicolumn{2}{|c|}{ Group B } & \multirow[t]{2}{*}{$P$ values } \\
\hline & male & female & male & female & \\
\hline \multirow[t]{4}{*}{ Length (cm) } & $5.21-8.51$ & $5.01-8.01$ & 7.01-8.81 & $6.01-8.01$ & Group A Male vs. Group B \\
\hline & $7.03 \pm .73$ & $6.57 \pm .77$ & $7.62 \pm .65$ & $7.01 \pm .54$ & Male- .025 \\
\hline & & & & & Group B Male vs. \\
\hline & & & & & Group B Female-.019 \\
\hline \multirow[t]{2}{*}{ Breadth (cm) } & $1.74-2.50$ & $1.50-2.80$ & $1.74-2.67$ & $1.94-2.44$ & \\
\hline & $2.10 \pm .27$ & $2.16 \pm .37$ & $2.24 \pm .29$ & $2.24 \pm .21$ & \\
\hline \multirow[t]{2}{*}{ Thickness (cm) } & $1-2$ & $1-2$ & $1-2$ & $1-2$ & \\
\hline & $1.27 \pm .46$ & $1.37 \pm .50$ & $1.29 \pm .47$ & 1.25 .45 & \\
\hline \multirow[t]{2}{*}{ Volume (ml) } & $15-30$ & $12-35$ & $22-35$ & $25-32$ & Group A Male vs. \\
\hline & $26.33 \pm 4.22$ & $26.37 \pm 5.16$ & $30.50 \pm 3.81$ & $29.08 \pm 2.47$ & Group B Male-.007 \\
\hline \multirow[t]{2}{*}{ Weight(gm) } & $3.80-9.20$ & $4.00-10.20$ & $6.00-10.20$ & $5.30-9.80$ & \\
\hline & 6.921 .57 & 6.821 .76 & 7.731 .40 & 6.821 .84 & \\
\hline
\end{tabular}

Results are shown in mean $\pm S D$, difference between mean were analyzed by unpaired t-test

$P$ value $P \leq 0.05$ was taken as significant

\section{Discussion}

In the present study the average length and breadth of the gall bladder was $6-7 \mathrm{~cm}$ and $2 \mathrm{~cm}$ respectively. The range of length of gall bladder was between 6 and $10 \mathrm{~cm}$ found by most of the authors ${ }^{9-21}$. Again the range of breadth of gall bladder was $3-4 \mathrm{~cm}$ found by the authors $9,10,11,13,14,15$ which was higher than the present study. The average of the volume was 26-29ml found in the present study which was somewhat lower than findings of the workers of the different parts of the world who found the range of volume was $30-50 \mathrm{ml}$ in most cases $^{9-12,15-24}$. But according to some author the volume was 40-70 $\mathrm{ml}^{25}$ and $100 \mathrm{ml}^{26}$. It is generally believed that Bangladeshi are shorter in height and low body mass index and for this reason mean length of the gallbladder might be less than foreign people.

So many of the authors in different parts of the world wrote in different text books and literatures about the morphology of the gallbladder but none of them have mentioned about the age or sex of the study people whom these values represent. They did not mention whether these data were collected from living individual during surgery or from cadaver or from ultrasonography. From the results of the present study it could be assumed that when comparison was made between males of group A and group B it was found that though all the mean values of morphological parameters were higher in group $B$ than group $A$ and reached $a$ significantly higher level for length and volume only. Also the females had higher mean values for all parameters in group $B$ than group $A$ but the thickness of gallbladder was high in group $A$ than group B though no values differ significantly.

Again when comparison was made between male and females of group A it was found that the mean values of length and weight was higher in male but mean values of breadth, thickness and volume was higher in females but regarding comparison of males and females of group B, males showed higher mean values for all parameters than the corresponding female group, though no values differ significantly.

The higher mean values of different parameters of the gallbladder in elderly males and also from their female counterparts of the same age groups may 
be due to shorter size of the females. Again some parameters showed higher values in females (breadth, thickness and volume) which may indicate the predominance of cholelithiasis in females. Again most of the values in male and female of elderly were higher than the younger groups indicate the formation of gallstones in elderly. In a study regarding volume of gallbladder CaroliBosc $^{27}$ found that the volume of the gallbladder was increased significantly in subjects over 50 years. They also found a positive correlation between gallbladder volume and body surface area. It may be assumed that in elderly the length was increased might be due to increase in the capacity and thickness of the gallbladder. Larger gallbladder may predispose stasis of bile ${ }^{7}$.

The wall of the gallbladder may become thickened and fibrotic in chronic cholecystitis accompanied with chronic cholelithiasis which may prevent the gallbladder from contracting and expanding normally ${ }^{28}$. In the present study on postmortem gallbladder it was not possible to find any history of chronic cholecystitis or any other gallbladder disease which may cause the increase in the thickness of the gallbladder wall in the younger females than the other groups.

\section{References}

1. Wikipedia contributors. Gallbladder [Internet]. Wikipedia, The Free Encyclopedia; 2008 Nov 11, 02:49 UTC [cited 2008 Nov 13]. <http:// en.wikipedia.org/w/index.php?title= Gallbladder\&oldid $=251019352$

2. New World Encyclopedia contributors. Gallbladder [Internet]. New World Encyclopedia; 2008 Apr 3, 20:42 UTC [cited 2008 Nov 12]. < http://www.newworldencyclopedia.org/entry/Gallbladder? oldid= 686020>

3. Zahrani IH and Mansoor I. Gallbladder pathologies and cholelithiasis. Sauidi Med J. 2001; 22(10): 885-89.

4. Bekele $Z$ and Tegegn K. Cholecystitis. Ethiop Med J. 2002 Jul;40(3):pp.209-16 ttp:// www.thedoctorsdoctor.com/diseases/ gallbladder_chronic_cholecystitis.httm

5. Neri $\mathrm{V}$, Ambrosi A, Fersini A, Tartaglia $\mathrm{N}$ and Valentino TP. "Antegrade dissection in laparoscopic cholecystectomy". JSLS :
Journal of the Society of Laparoendoscopic Surgeons / Society of Laparoendoscopic Surgeons 2007; 11(2): 225-28.

6. Ibingira CBR. Gross Anatomical variations and congenital anomalies of surgical importance in hepatobiliary surgery in Uganda. East and Central African Journal of Surgery 2006 April; 12(1): 93-98.

7. Sanjay N. Anatomy relevant to cholecystectomy. Journal of Minimal Access Surgery 2005 April-June;1(2):53-58.

8. Wikipedia contributors, 'Middle age', Wikipedia, The Free Encyclopedia, 31 December 2009, 01:06 UTC, <http:// en.wikipedia.org/w/index.php?title= Middle age \&oldid $=335016578>$ [accessed 18 January 2010]

9. Becker RF et al. The Anatomical Basis of Medical practice. 1st ed, Baltimore, USA: The Williams \&Wilkins Company 1971. 602-03.

10. Woodburne RT. Essentials of Human Anatomy. 5th edn. New York: Oxford university press 1973. 419-20

11. Romanes GJ. Cunningham's textbook of anatomy. 12th edn. New york: Oxford University press 1981. 481-85.

12. Basmajian JB. Grant's method of anatomy. 11th edn. Baltimore USA: Williams \& Wilkins 1989. 156-57.

13. Tarsoli A, Corazziari E, Habib FI and Cicala M., Gallbladder location, Gallbladder function. Gastroenterol Suppl. 1990; 175: 52-57.

14. Meilstrup JW. Imaging Atlas of the Normal Gallbladder and Its Variants. Boca Raton: CRC Press 1994. 4.

15. Russell RCG, Williams NS, Bulstrode CJK.(eds). Baley's \& Loves short practice of surgery. $23^{\text {rd }}$ edn. London: Arnold, a member of the Holdder headline group 2000. 965-96.

16. Boro B. Gall Bladder, Its Function in human body. Articlesbase. 04-08-2006. Views: 277. < www.articlesbase.com/advicearticles/ gallbladderits function-in-human-body45787.html > 
17. Seymour I, Schwartz F, Charles B, Dana K and Andersen. Manual of Surgery. $8^{\text {th }}$ edn. McGraw-Hill Professional 2006. 821.

18. Moore $\mathrm{KL}$ and Dalley AF. Clinically oriented anatomy. 5th ed. Baltimore: Lippincott Williams \& Wilkins 2006. 302-03

19. Borley NR. Ed. Abdomen and Pelvis. In: Boreli NR, Collins P, Crossman SR, Gatzoulis MA, Healy JC, Johnson D, et al. eds. Gray's anatomy: The anatomical basis of clinical practice. $40^{\text {th }}$ edn. Spain: Churchill Livingstone Elsevier 2008. 1177-81.

20. Wikipedia contributors. Gallbladder [Internet]. Wikipedia, [2009 Sep 29]; 05:22 UTC [cited 2009 Nov 9]. Available from: http://simple. wikipedia.org/w/index.php?title= Gallbladder\&oldid=1761406.

21. Snell RS. Clinical Anatomy for Medical student, $5^{\text {th }}$ edn. Boston: Little Brown \& company 1995. 219.

22. Sinnatamby CS. Last's anatomy. Regional and applied. 10th ed. Edinburgh London: Churchill Livingstone 1999. 257-58.
23. Junqueira LC and Carneiro J. Basic histology. Text and atlas. 10thed. USA: McGraw-Hill Companies, Inc. 2003. 345.

24. Ross $\mathrm{MH}$, Kaye $\mathrm{Gl}$ and Pawlina W. Histology: A text and atlas. 4th ed. Baltimore: Lippincott Williams \& Wilkins 2003. 548-51.

25. PathologyOutlines.com. Gallbladder Home Page. Printer Friendly Version <www. pathologyoutlines.com/gallbladder. htm>2004

26. Burkitt HG, Young B and Heath JW. Wheater's functional histology:text and colour atlas, $3^{\text {rd }}$ edn. Edinburgh London: Churchill Livingstone 1993. 278.

27. Caroli-Bosc FX, Pugliese P, Petein EP, Demarquay JF, Montet JC and Hastier. Gallbladder Volume in Adults and Its Relationship to Age, Sex, Body Mass Index, Body Surface Area and Gallstones. Digestion. France 1999; 60(4): 344-48.

28. Person GE, Ros AG and Thulin AJ. Surgical treatment of gallstones:changes in a defined population. Eur J Surg. 2002; 1168(1): 13-17. 